Revista Brasileira de Cartografia

ISSN 1808-0936 | https://doi.org/10.14393/revbrascartogr

Sociedade Brasileira de Cartografia, Geodésia, Fotogrametria e Sensoriamento Remoto

\title{
Metodologia Desenvolvida para o Posicionamento Geodésico de Zona Especial Aeroportuária: Estudo de Caso do Aeroporto Internacional do Recife/Guararapes - Gilberto Freyre
}

\author{
Methodology Developed for the Geodetic Positioning of Special Airport Zone: Case Study \\ of Recife/Guararapes International Airport - Gilberto Freyre
}

Raimundo Nonato Camilo Neto ${ }^{1}$ e Andréa de Seixas ${ }^{2}$

1 Universidade Federal de Pernambuco, Departamento de Engenharia Cartográfica, Recife, Brasil. E-mail: c_neto26@hotmail.com ORCID: https://orcid.org/0000-0002-5350-876X

2 Universidade Federal de Pernambuco, Departamento de Engenharia Cartográfica, Recife, Brasil. E-mail: aseixas@ufpe.br ORCID: https://orcid.org/0000-0002-5879-4902

Resumo: A Zona Especial do Aeroporto (ZEA) é uma região de diretrizes específicas que procura compatibilizar a legislação de uso e ocupação do solo municipal com as orientações referentes ao Plano de Proteção do Aeródromo regulamentado por legislação Federal. Com o crescimento e adensamento das edificações no entorno de Aeroportos se faz necessário um controle posicional e dimensional das obras visando atender as legislações em vigor. Este trabalho tem o objetivo de apresentar uma metodologia desenvolvida para o posicionamento geodésico de Zona Especial Aeroportuária usando como estudo de caso o Aeroporto Internacional do Recife/Guararapes-Gilberto Freyre. Para a localização dos Vértices Virtuais dos cruzamentos das vias que compõem a poligonal da ZEA foram implantados pontos de referência empregando o método de posicionamento GNSS (Relativo Estático), definindo em seguida um Sistema Geodésico Local para a determinação de pontos-objeto delimitadores de meios-fios empregando o método de posicionamento GNSS/RTK e identificação dos eixos das vias e respectivas interseções. Ao final deste trabalho são determinados os Vértices Virtuais de um trecho da poligonal da ZEA com a análise qualitativa de gabarito e identificação de áreas de conflitos, indicando recomendações quanto aos critérios posicionais adequados à implantação de empreendimentos no entorno do Aeroporto. O posicionamento GNSS dos pontos de referência em módulo atingiu um desvio padrão na ordem $\leq 11 \mathrm{~mm}$, com erro de fechamento da rede dos triângulos formados com discrepância máxima na horizontal de $9 \mathrm{~mm}$ e na vertical de $29 \mathrm{~mm}$. Os pontos-objeto determinados com GNSS/RTK alcançaram um desvio padrão em módulo na ordem $\leq 18 \mathrm{~mm}$.

Palavras-chave: Levantamento Geodésico. Posicionamento GNSS. Plano de proteção de aeródromo. Vértices Virtuais. Interseções de reta.

\begin{abstract}
The Special Airport Zone (SAZ) is a region of specific guidelines which seeks to harmonize the county land use and occupancy legislation with the recommendations related to the Aerodrome Protection Plan regulated by Federal legislation. With increase and densification of the buildings around Airports, it becomes necessary a positional and dimensional control of the construction works in order to comply with the current legislation. This work aims to present a methodology developed for the geodetic positioning of the Special Airport Zone using the Recife / Guararapes-Gilberto Freyre International Airport as a case study. For the location of the virtual vertices of pathways intersections which is part of the SAZ traverse, reference points were placed by using the GNSS (Relative Static) positioning method, followed by a definition of a Local Geodetic System for the determination of points objects to delimit curbs applying the GNSS/RTK positioning method and identification of pathways axes and intersections respectively. At the end of this work the virtual vertices of a section of the SAZ traverse are determined, followed by a high standard qualitative analysis and identification of conflict areas, pointing recommendations regarding the positional criteria appropriate to the implementation of projects in the surroundings area of the Airport. The GNSS positioning of the reference points in module reached a standard deviation in the order $\leq 11 \mathrm{~mm}$, with the error of closing the network of the triangles formed with maximum discrepancy in the horizontal of $9 \mathrm{~mm}$ and in the vertical of $29 \mathrm{~mm}$. The object points determined with GNSS/RTK reached a standard deviation in modulus of $\leq 18 \mathrm{~mm}$.
\end{abstract}

Keywords: Geodetic Survey. GNSS Positioning. Aerodrome Protection Plan. Virtual Vertices. Line intersections. 


\section{INTRODUÇÃo}

A Prefeitura Municipal da Cidade do Recife estabeleceu através da Lei $n^{\circ} 16.414$, de 29 de julho de 1998, a Zona Especial do Aeroporto - ZEA, uma zona de diretrizes específicas que dispõe sobre as condições de Uso e Ocupação do Solo e suas implicações nas áreas de entorno do Aeroporto Internacional do Recife/Guararapes - Gilberto Freyre, em Recife, no Estado de Pernambuco. Neste contexto a política de desenvolvimento urbano dessas áreas é balizada por legislações compartilhadas, e muitas vezes sobrepostas, no que diz respeito principalmente aos interesses de segurança e proteção ao espaço aéreo do Aeroporto. $\mathrm{O}$ Comando da Aeronáutica, através da Portaria no 957/GC3, de 09 de junho de 2015, já dispõe sobre as restrições aos objetos projetados no espaço aéreo, que possam afetar adversamente a segurança ou a regularidade das operações aéreas.

A Zona Especial do Aeroporto (ZEA) do município do Recife é composta pela área onde se encontra situado o Aeroporto Internacional do Recife e pelas áreas de seu entorno que requerem tratamento diferenciado quanto ao seu uso e ocupação do solo, visando conter principalmente a densidade populacional e a compatibilização com as Leis específicas da região. O planejamento e o posicionamento da ZEA perpassam por questões técnicas, sociais, econômicas e legais, necessitando de maior publicidade com parâmetros claros que possibilitem a viabilidade de estudos prévios de construções e ocupações nas áreas próximas dos sítios aeroportuários. Para gerenciar e restringir as regiões aeroportuárias, as autoridades contam principalmente com a ZEA, com o Plano Básico de Zona de Proteção de Aeródromo (PBZPA), que estabelecem os gabaritos para construção ou limites posicionais permitidos, além do Plano de Zona de Ruído (PZR) que define regiões específicas para tratamento acústico adequado ou uso restrito que não comprometa a segurança, a saúde e o bem estar da população circunvizinha.

Uma análise espacial de um trecho da Zona Especial do Aeroporto - ZEA, regulamentada pela Lei Municipal $\mathrm{n}^{\circ} 16.414$, de 29 de julho de 1998 e suas implicações, quanto às restrições de ocupação tridimensional, nas áreas de entorno do Aeroporto Internacional do Recife/Guararapes no Estado de Pernambuco foi abordada em Camilo Neto (2018).

Neste contexto, é apresentado neste trabalho o emprego de tecnologias que garantam a confiabilidade posicional das obras em relação ao zoneamento e métodos de obtenção dos dados de posicionamento geodésico com exatidão compatível com as tolerâncias expressas nas normas técnicas.

Os Métodos com base no Global Navigation Satellite System (GNSS), tais como: Posicionamento Relativo Estático e Posicionamento Relativo Cinemático em Tempo Real ou Real Time Kinematic (RTK) são métodos adequados à execução e acompanhamento de levantamentos geodésicos de objetos (SEEBER, 2003; MONICO, 2008). Neste trabalho, apresenta-se uma metodologia desenvolvida para o posicionamento geodésico de Zona Especial Aeroportuária e áreas relacionadas à ZEA.

A área de estudo compreende um trecho que compõe parte da ZEA, localizada próxima ao aeroporto, no bairro de Boa Viagem, no Município do Recife, no Estado de Pernambuco. Nesta área, foram implantados pontos de referência que serviram de apoio aos levantamentos com o posicionamento por GNSS. Com os pontos de referência implantados foram levantados os pontos-objeto para detalhamento e caracterização dos cruzamentos das vias e com os dados processados dos cruzamentos foram estabelecidos os Vértices Virtuais dos trechos da ZEA.

A contribuição deste trabalho diz respeito a identificação e aplicação das leis nacionais envolvidas com a ZEA e o emprego da Geodésia Aplicada, em um estudo de caso real, com a materialização de pontos georreferenciados, que possibilitam a consulta ou fiscalização de dados cadastrais de imóveis em áreas municipais, proporcionando segurança nos parâmetros urbanísticos para engenharia nas construções de novas edificações ou pré-existentes. Apresentando-se uma metodologia para o posicionamento geodésico de Zona Especial Aeroportuária e a localização dos Vértices Virtuais dos cruzamentos das vias que compõem a poligonal de um trecho da ZEA em estudo, aplicando-se métodos de posicionamento GNSS.

A utilização de geotecnologias para a análise geoespacial de ZEA, além do estudo do uso e ocupação das áreas adjacentes a mesma não é recente, pois construções aeroportuárias requerem este tipo de estudo e análise espacial. $\mathrm{O}$ advento de novas tecnologias de medição e aquisição de dados geoespaciais promovem estudos de novos métodos e adaptações que possibilitam a elaboração de produtos cartográficos $3 \mathrm{D}$ de 
qualidade, aperfeiçoando-se assim, a visualização espacial e procedimentos automatizados para a detecção de possíveis áreas de risco e inapropriadas para sua ocupação e uso. Internacionalmente esta temática é bastante difundida.

Em Falavigna, Iescheck e Souza (2020) é apresentada uma metodologia para análise e seleção de dados geoespaciais, modelagem de dados e a análise espacial da performance para a geração de modelos 3D para a análise em zona de proteção de aeródromo. Como área de estudo, apresenta-se o entorno do aeroporto internacional Salgado Filho, em Porto Alegre, no estado do Rio Grande do Sul. A partir do limite estabelecido para a altimetria edificada foi possível quantificar através do modelo 3D gerado áreas críticas de imóveis construídos que ultrapassam essa margem altimétrica localizados ao redor desse aeroporto. Para essa análise foram extraídos dados de cartas topográficas, ortofotocartas e dados LiDar (Light Detection and Ranging). Iescheck e Oliveira (2011) apresentam uma metodologia para a implementação de um Sistema de Informação Geográfica na área do PBZPA deste aeroporto internacional, envolvendo desde os dados de entrada, a edição gráfica, processamentos, análise espacial, seguindo os resultados, com emprego de modelagem tridimensional.

Em Contreras-Alonso et al. (2020), aborda-se o emprego de um Sistema de Informação Geográfica do aeroporto da Cidade de Barcelona, Espanha, e apresenta uma série de superfícies de limitação de obstáculos 3D, que define os limites aos quais os objetos podem se projetar no espaço aéreo, a fim de configurar o espaço aéreo em torno dos aeródromos que devem ser mantidos livre de obstáculos. O estudo apresentado se concentra em medir a altura e geolocalização de obstáculo, a fim de determinar sua influência sobre a superfície de limitação de obstáculos e na determinação das ações subsequentes, que precisam ser tomadas para evitar que se torne um risco à segurança operacional.

Segundo Distefano, Leonardi e Buscema (2007), a implementação da política de Zona de Segurança Pública em aeroportos civis é baseada em um modelo de trabalho realizado usando dados apropriados de acidentes de aeronaves para determinar o nível de risco para as pessoas nas proximidades dos aeroportos. Neste contexto, os autores apresentam uma proposição de metodologia para definir a política de Zonas de Segurança Pública aplicada para o aeroporto internacional de Catania, na ilha de Cicília, na Itália. De acordo com os mesmos autores as Zonas de Segurança Pública são áreas de terreno no final das pistas de maior movimento dos aeroportos, nos quais o desenvolvimento é restrito, a fim de controlar o número de pessoas no solo com risco de morte ou ferimentos em caso de acidente de aeronave na decolagem ou aterrissagem.

O estudo do posicionamento geodésico de ZEA e sua integração ao cadastro e principalmente em áreas urbanas possibilita a implementação de métodos de determinação de coordenadas consolidados e o desenvolvimento de metodologias com novas geotecnologias que possam conduzir ao aperfeiçoamento de técnicas de medição em locais, onde a obstrução de sinais devido à presença maciça de edificações prediais são evidentes. Neste sentido, estudos envolvendo Redes-RTK (WILLGALIS et al., 2003; ALVES et al., 2011), melhoria na acurácia do posicionamento (ANDRADE; ALVES, 2016), critérios de integridade em posicionamento GNSS em área urbana (ZHU; MARAIS; BETAILLE; BERBINEAU, 2018), dentre outros, podem ser conduzidos para o seu aperfeiçoamento.

\section{EMBASAMENTO LEGAL E TÉCNICO DA ZEA}

A ZEA é regulamentada pela Lei Municipal n 16.414, de 29 de Julho de 1998 (RECIFE, 1998), que dispõe sobre as condições de uso e ocupação do solo e integra o elenco das Zonas Especiais, previsto na Lei Municipal de $n^{\circ} 17.511 / 2008$, Plano Diretor, da cidade do Recife (RECIFE, 2008), que deverão obedecer também aos parâmetros previstos no Plano Específico de Zoneamento de Ruído (PEZR - REC/PE) deste município e no PBZPA, elaborados pelas autoridades aeronáuticas.

O PBZPA para o Aeroporto Internacional do Recife, aprovado através da Portaria de $n^{\circ}$ 957/GC3, de 9 de julho de 2015 (BRASIL, 2015), dispõe sobre as restrições aos objetos projetados no espaço aéreo que possam afetar adversamente a segurança ou a regularidade das operações aéreas e destaca a competência da administração Municipal/Distrital, que deve compatibilizar o adequado ordenamento territorial, mediante planejamento e controle do uso, do parcelamento e da ocupação do solo urbano dentro de seus limites.

O Brasil participa de acordos internacionais, inclusive atende a convenção da Organização de 
Aviação Civil Internacional (OACI), que passou a integrar a Organização das Nações Unidas (ONU) e padroniza, através de normas e regulamentações, o desenvolvimento e as diversas atividades envolvidas no âmbito da Aviação Civil de maneira segura e sistemática (CAMILO NETO e DE SEIXAS, 2016).

O Aeroporto do Recife possui todas as áreas previstas na Convenção Internacional (Figura 1).

Figura 1 - Vista superior das superfícies limitadoras de obstáculos e o PBZPA do Aeroporto.
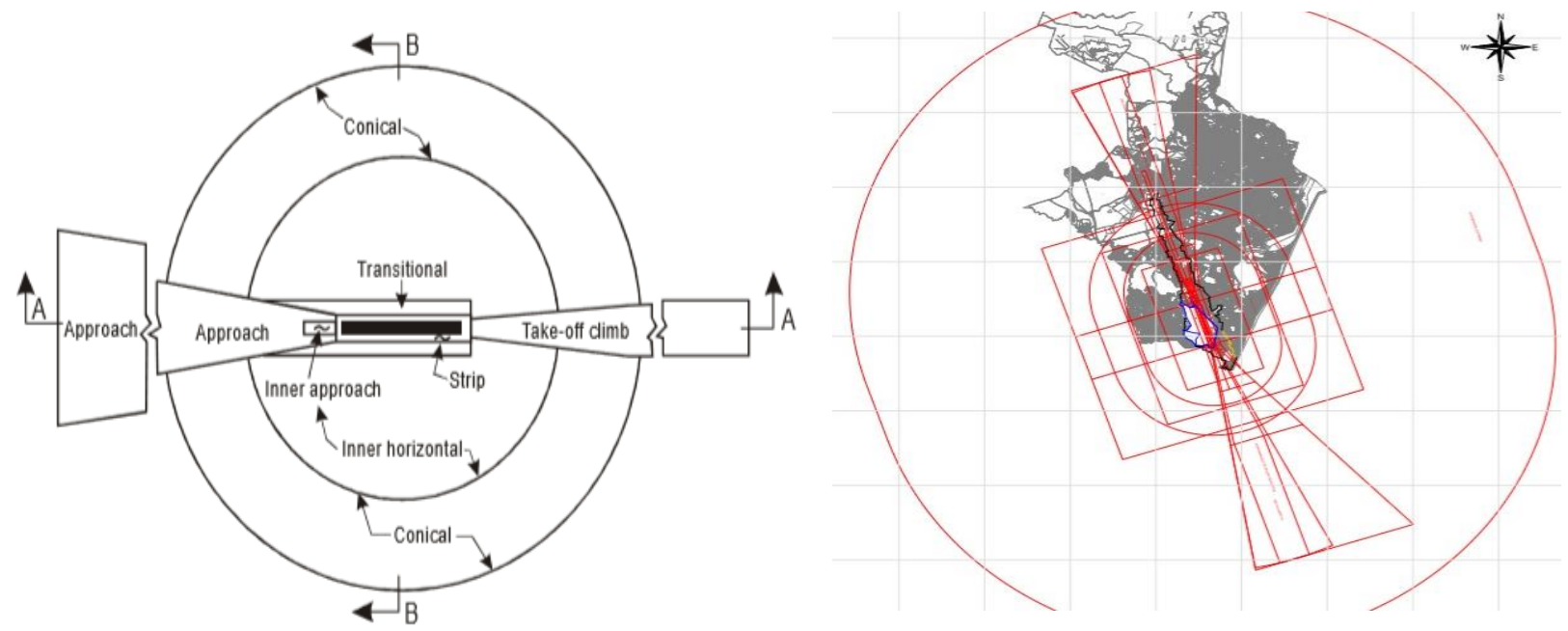

Fonte: Internacional Civil Aviation Organization (2009) e (BRASIL, 2015).

\subsection{Lei Municipal $n^{\circ} 16.414$, de 29 de julho de 1998 (RECIFE, 1998)}

O documento principal identificado para balizar o estudo de ruído em Recife foi a Portaria DAC $\mathrm{n}^{\circ}$ 232/DGAC/97 (BRASIL, 1997), do antigo Departamento de Aviação Civil (DAC) que também foi utilizado como parâmetro para o Regulamento Brasileiro da Aviação Civil (Figura 2).

Figura 2 - Plano Específico de Zoneamento de Ruído para Recife (PEZR) em 1997 e 2016.
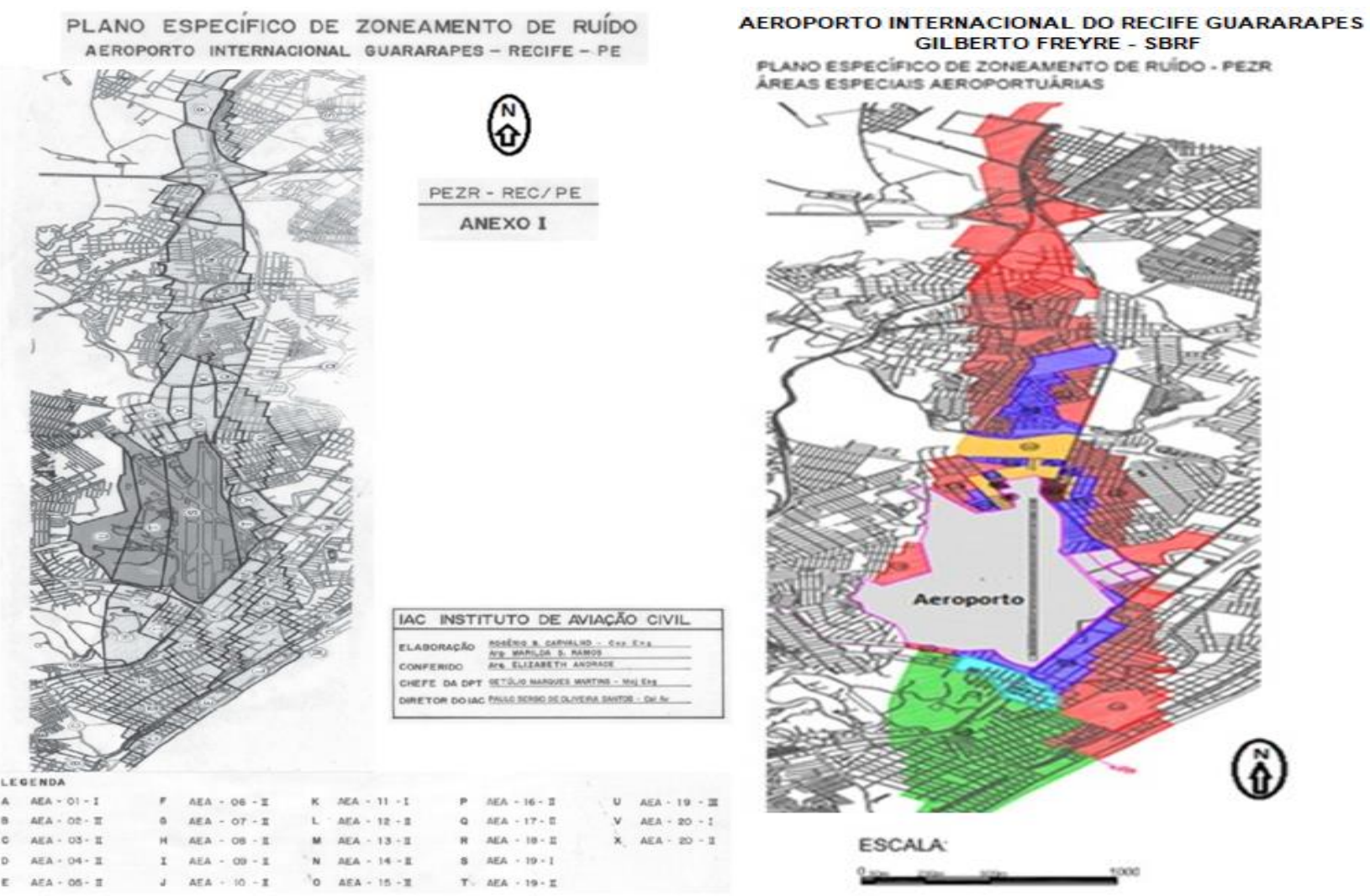

Fonte: Portaria DAC nº 232/DGAC (BRASIL, 1997) e Portaria n 1.255/SAI, (BRASIL, 2016). 
No Município de Recife, a ZEA tem seu perímetro externo atualmente descrito e delimitado conforme mapa aprovado pela ANAC e desenvolvido em conformidade com a Portaria $\mathrm{n}^{\circ}$ 1.255/SIA, de 20 de maio de 2016 (BRASIL, 2016), que validou as curvas de ruído do Aeroporto Internacional do Recife, mediante acordo de cooperação técnica entre o município, a Aeronáutica e a INFRAERO, nos termos do Regulamento Nacional de Aviação Civil (RBAC).

A Prefeitura Municipal da Cidade do Recife (PMCR) utilizando a descrição proposta pelo DAC aprovou a Lei $\mathrm{n}^{\circ}$ 16.414, de 29 de julho de 1998 (RECIFE, 1998), que dispõem sobre as condições de Uso e Ocupação do Solo na ZEA e relata a localização dos pontos de sua poligonal.

A Tabela 1 apresenta o quadro resumo das legislações de forma cronológica e mostra as normativas nacionais envolvidas com a ZEA.

Tabela 1 - Quadro Resumo das Legislações.

\begin{tabular}{|c|c|c|}
\hline Ano & Legislação & Contexto \\
\hline 1946 & Lei ${ }^{\circ} 21.713$, de 27/08/1946 & $\begin{array}{l}\text { Promulga a Convenção sobre Aviação Civil Internacional em Chicago, } \\
\text { 7.12.1944, e firmado pelo Brasil, em Washington, a } 29 \text { de maio de } 1945 .\end{array}$ \\
\hline 1986 & 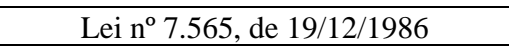 & Dispõe sobre o Código Brasileiro de Aeronáutica. \\
\hline 1987 & 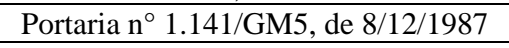 & Dispõe sobre as Zonas de Proteção (PBZPA e PBZR). \\
\hline 1988 & Constituição de 1988, de 05/10/1988 & Constituição da República Federativa do Brasil. \\
\hline 1996 & Lei $\mathrm{n}^{\circ} 16.176$, de 09/05/1996 & Estabelece a Lei de Uso e Ocupação do Solo da Cidade do Recife - LUOS. \\
\hline 1997 & Portaria n ${ }^{\circ}$ 232/DGAC, de 14/04/1997 & $\begin{array}{l}\text { Aprova o Plano Específico de Zoneamento de Ruído do } \\
\text { Aeroporto Internacional dos Guararapes - PE. }\end{array}$ \\
\hline 1998 & Lei n 16.414 , de 29/07/1998. & $\begin{array}{l}\text { Dispõe sobre as condições de Uso e Ocupação do Solo na Zona Especial } \\
\text { do Aeroporto (ZEA). }\end{array}$ \\
\hline 2005 & Lei ${ }^{\circ} 11.182$, de $27 / 09 / 2005$ & Cria a Agência Nacional de Aviação Civil (ANAC). \\
\hline 2005 & Portaria n ${ }^{\circ}$ 76/DGCEA, de 09/06/2005 & $\begin{array}{l}\text { Aprova o Plano Específico da Zona de Proteção do Aeródromo de } \\
\text { Recife/Guararapes - Gilberto Freyre. }\end{array}$ \\
\hline 2008 & Lei $^{\circ} 17.511$, de $29 / 08 / 2008$ & Plano Diretor do Município do Recife. \\
\hline 2011 & 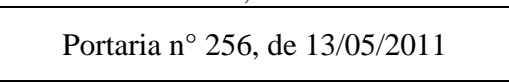 & $\begin{array}{l}\text { Dispõe sobre as restrições relativas às implantações que possam afetar } \\
\text { adversamente a segurança e a regularidade das operações aéreas. }\end{array}$ \\
\hline 2013 & Resolução nº 281, de 10/09/2013 & Regulamento Brasileiro da Aviação Civil no 161 \\
\hline 2015 & Portaria $N^{\circ} 957 / G C 3$, de 9/07/2015 & $\begin{array}{l}\text { Dispõe sobre as restrições aos objetos projetados no espaço aéreo que } \\
\text { possam afetar adversamente a segurança das operações aéreas. }\end{array}$ \\
\hline 2016 & Portaria $\mathrm{n}^{\circ} 1.255 / \mathrm{SIA}$, de 20/05/2016 & $\begin{array}{l}\text { Valida curvas de ruído para o Aeroporto Internacional Guararapes, } \\
\text { localizado em Recife/PE (SBRF). }\end{array}$ \\
\hline
\end{tabular}

Fonte: Camilo Neto (2018).

\section{POSICIONAMENTO GEODÉSICO DA ZEA}

O posicionamento geodésico da ZEA envolve a abordagem do Sistema Geodésico de Referência (SGR), para a descrição dos vértices delimitadores da ZEA no Sistema Geodésico oficial do país, as transformações de coordenadas Geocêntricas para o Sistema Geodésico Local (SGL), a definição dos pontos de referência e pontos-objeto, envolvidos na caracterização das áreas delimitadoras da ZEA através de métodos geodésicos e a determinação dos pontos dos Vértices Virtuais (VV) da ZEA, que se dá a partir da interpretação geométrica dos cruzamentos dos eixos das vias.

No Brasil, o Sistema Geodésico de Referência (SGR) oficial é o Sistema de Referencia Geocêntrico para as Américas (SIRGAS2000), que emprega a densificação do Internacional Terrestrial Reference Frame (ITRF 2008), do elipsoide de referência Geodetic Reference System (GRS 80). O Sistema Geodésico Brasileiro (SGB) é constituído pelas redes planimétrica, altimétrica e gravimétrica espaçada por todo o território (IBGE, 2005).

Neste SGR as Coordenadas Geodésicas Cartesianas Geocêntricas (X, Y, Z) de um ponto na superfície da Terra podem ser expressas em Coordenadas Geodésicas Elipsoidais (latitude - $\phi$, longitude - $\lambda$ e altitude elipsoidal - h), em coordenadas planorretangulares UTM (E, N, h) e em Coordenadas Geodésicas Cartesianas Locais (x, y, z). Por meio de conversão geodésica de coordenadas utilizando modelos matemáticos é possível representar um mesmo ponto na sua superfície terrestre a partir destas coordenadas.

As Coordenadas Geodésicas Cartesianas Geocêntricas são fornecidas no posicionamento GNSS e devem ser transformadas em Coordenadas Geodésicas Cartesianas Locais para atenderem os trabalhos 
geodésicos e implementação de projetos em engenharia e de cadastro destinados a constituir uma infraestrutura de apoio geodésico e topográfico, fazendo-se necessário o uso de um sistema de coordenadas terrestres locais que permita o planejamento, a implantação de obras e de plantas cadastrais (SILVA et al., 2015).

A Rede de Referência Cadastral Municipal é regulamentada no Brasil pela NBR 14166/98 (ABNT, 1998). Nesta normalização é estabelecida a transformação das coordenadas dos pontos entre o Sistema Geodésico Global e o Sistema Geodésico Local através da aplicação da equação de Puissant. Para a realização dessas transformações entre coordenadas, outros estudos, sugerem a aplicação da metodologia que emprega a matriz de rotação e as translações (modelagem 3D) discutida em (GARNÉS, SIQUEIRA e CACHO, 2005) e (DAL'FORNO et al., 2010). Neste trabalho a transformação de coordenadas geocêntricas em coordenadas no Sistema Geodésico Local foi realizada pelo método de rotações e translações.

Os dados coletados podem ser processados após a coleta (pós-processados) ou no momento da coleta (tempo real). No Posicionamento Relativo Cinemático em Tempo Real (RTK) é necessário que a estação móvel disponha de link de rádio ou outro tipo de sistema similar, e que o receptor da estação tenha o software adequado para o processamento dos dados coletados em tempo real. Assim, os dados que serão coletados na estação de referência irão para a estação móvel.

Para realizar esse tipo de posicionamento, os receptores base e o rover (móvel) rastreiam simultaneamente os satélites, onde a antena do receptor base ocupará um ponto com coordenadas conhecidas e os dados coletados neste ponto serão transmitidos para o receptor rover através de um link de rádio ou de outro tipo de comunicação, como por via protocolo de internet, Networked Transport of RTCM via Internet Protocol (NTRIP) (SOUZA, GARNÉS, MARQUES, 2014).

A Figura 3 mostra, que no método RTK as informações do receptor rover, com coordenadas desconhecidas serão corrigidas e fornecidas no momento do levantamento, a partir das coordenadas da antena do receptor base, já conhecidas.

O levantamento dos pontos-objeto dos cruzamentos das vias possibilita a definição dos eixos das vias in loco trazendo a necessidade da determinação do eixo virtual através dos cálculos e elementos da geometria analítica. Recomenda-se, neste caso, determinar as coordenadas dos pontos de cruzamento aplicando o método da interseção de retas conforme descrito em Kahmen e Faig (1988).

Figura 3 - Posicionamento Relativo Cinemático em Tempo Real - RTK convencional.
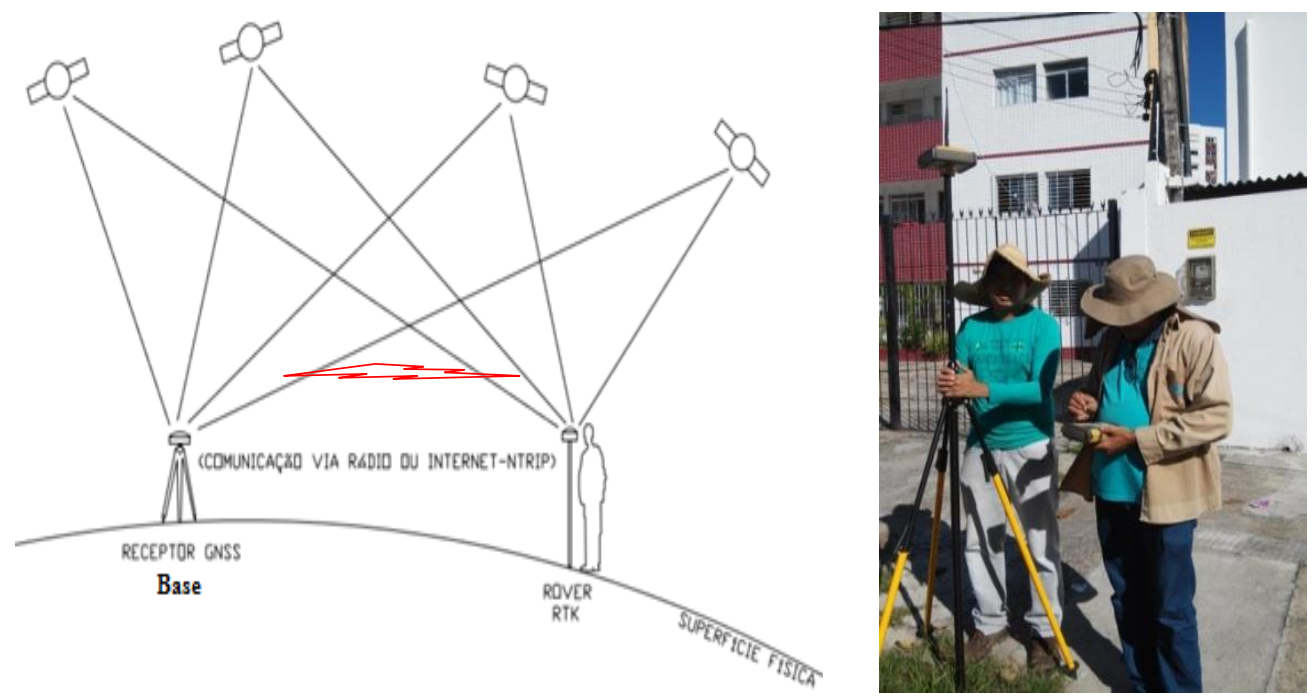

Fonte: Camilo Neto (2018).

Figura 4 ilustra a possibilidade de localização do ponto P (Vértice Virtual) através da interseção do prolongamento de duas retas. 
Figura 4 - Localização do ponto P a partir do prolongamento de retas.

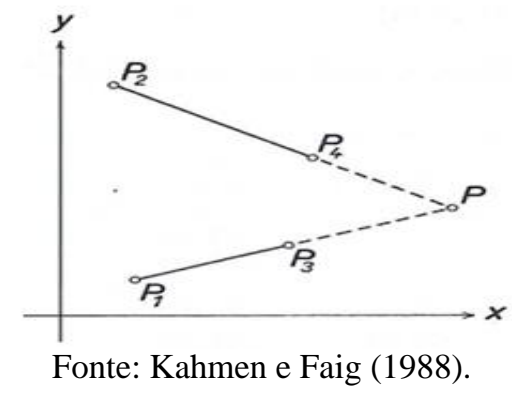

\section{MATERIAIS E MÉTODOS}

Para os métodos empregados foram utilizados equipamentos e softwares para a realização dos trabalhos de campo, processamentos e respectivas análises dos resultados.

\section{1 Área de Estudo e Recursos Tecnológicos}

A área de estudo compreende um trecho que compõe parte da Zona Especial do Aeroporto (ZEA), localizada no bairro de Boa Viagem, no Município do Recife, no Estado de Pernambuco. Nesta área foram implantados 6 pontos de referência por meio de pinos de aço, onde cada pino foi colocado próximo a cada Vértice Virtual da poligonal da ZEA para posterior levantamento do cruzamento. Os pinos foram denominados respectivamente, $\mathrm{CS} 1, \mathrm{CC} 2, \mathrm{CV} 3, \mathrm{~EB} 4, \mathrm{BD} 5$ e BA6, onde as letras representam as iniciais das ruas em que se cruzam (CAMILO NETO, 2018).

Os pontos de referência foram georreferenciados usando o Método de posicionamento GNSS Relativo Estático. O trecho segue desde a Rua Cruzeiro do Forte, após o canal de Setubal até a Rua Adauto C. Leal, próxima a via férrea do metrô (Estação Aeroporto) e aeroporto internacional (Figura 5). A vantagem do posicionamento GNSS é que não é necessária a implantação de pontos de referência em todos os cruzamentos. O trecho da ZEA observado compreende 12 cruzamentos e 6 pontos de referência. Considerouse que cada ponto de referência deve ser implantado de forma a cobrir a área de pelo menos 3 cruzamentos.

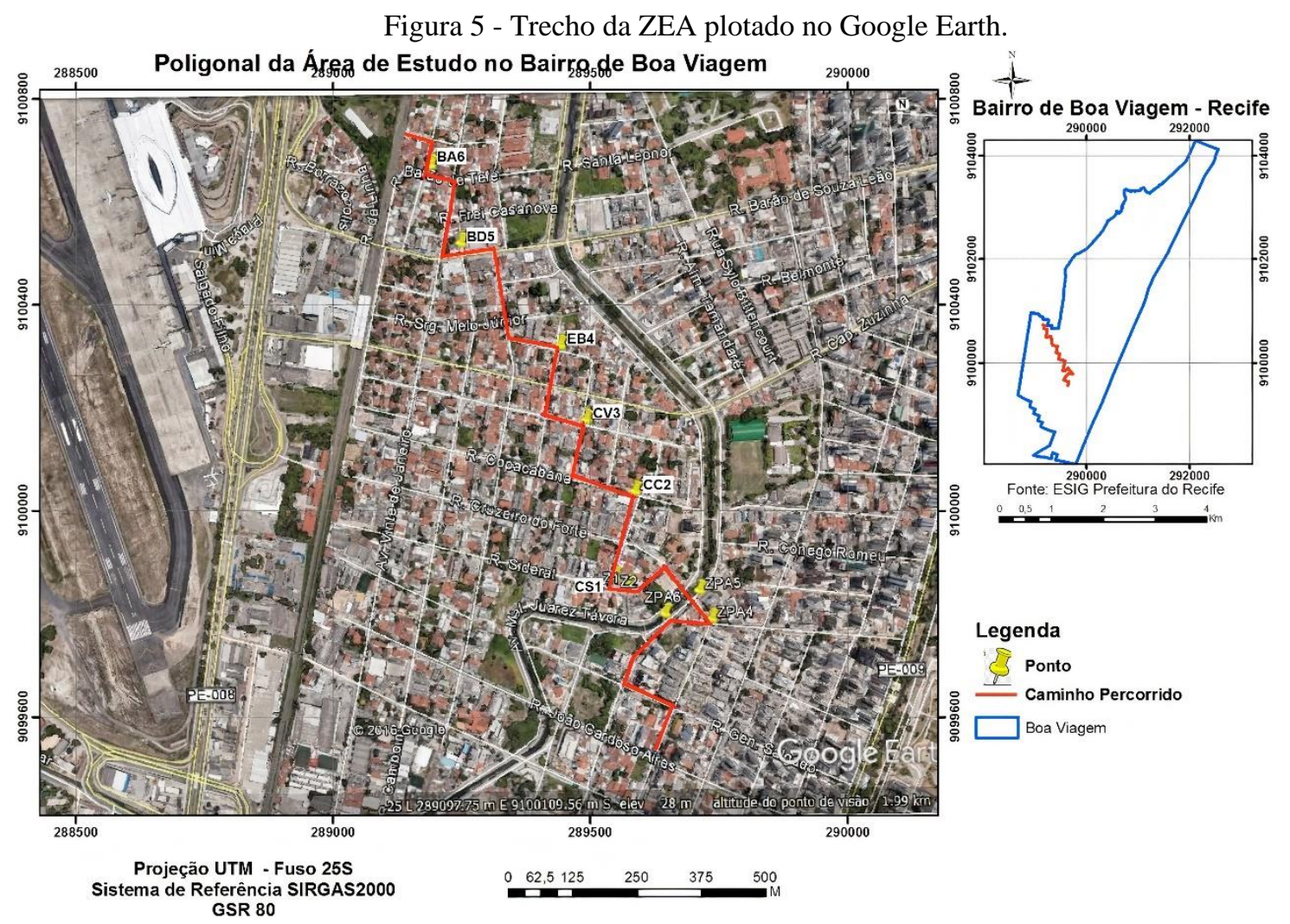

Fonte: Imagem adaptada do Google Earth (2017). 
A justificativa para adoção da área em questão é a sua proximidade do Aeroporto Internacional, região mais crítica da ZEA, quanto aos planos de proteção do Aeródromo e a imediação dos vértices conhecidos da Prefeitura Municipal da Cidade do Recife (PMCR), V12 e V13.

A determinação das coordenadas foi realizada com o emprego de receptores GNSS, projetos e plantas disponibilizados pelos órgãos públicos do Comando da Aeronáutica e da PMCR para a delimitação das áreas previstas na legislação. Além disso, foram utilizados os seguintes materiais de coleta e processamento de dados:

a) 01 (um) par de receptores GNSS HIPER LITE+: dupla frequência (L1 e L2), rádio com alcance de até $2 \mathrm{~km}$ em RTK, com precisão horizontal nominal de $\pm(3 \mathrm{~mm}+0,5 \mathrm{ppm})$ e vertical de $\pm(5 \mathrm{~mm}+0,5 \mathrm{ppm})$ para levantamentos estáticos e estáticos-rápidos e com precisão horizontal nominal de $\pm(10 \mathrm{~mm}+1 \mathrm{ppm})$ e vertical de $\pm(15 \mathrm{~mm}+1 \mathrm{ppm})$ para levantamentos cinemáticos e RTK (TOPCON, 2003);

b) 01 (um) par de receptores GNSS HIPER V: dupla frequência (L1 e L2), rádio com alcance de até $2 \mathrm{~km}$ em RTK, com precisão horizontal nominal de $\pm(3 \mathrm{~mm}+0,5 \mathrm{ppm})$ e vertical de $\pm(5 \mathrm{~mm}+$ $0,5 \mathrm{ppm})$ para levantamentos estáticos e rápido-estáticos e com precisão horizontal nominal de $\pm(10 \mathrm{~mm}+1 \mathrm{ppm})$ e vertical de $\pm(15 \mathrm{~mm}+1 \mathrm{ppm})$ para levantamentos cinemáticos e RTK (TOPCON, 2012);

c) softwares: AutoCad2016 (versão estudantil), ArcGis 10, TOPCOM TOOLS v.8.2 (com Hardlock do LAGEO/DECart), Excel 2010, AstGeoTop (GARNÉS, 2013) e (GARNÉS, 2017), TopconLink v.8.2.3 e Magnet Tools v.3.0;

d) base Cartográfica dos softwares ESIG, PMCR e Google Earth.

\subsection{Metodologia}

A seguir é feita a descrição dos procedimentos metodológicos adotados no desenvolvimento deste trabalho, seguindo o fluxograma apresentado na Figura 6. O fluxograma tem por objetivo a representação simplificada de uma série de etapas fundamentais da metodologia para a aplicação das técnicas abordadas. $\mathrm{Na}$ primeira etapa foi realizado um levantamento bibliográfico e estudo da legislação. Em seguida foi definida a localização da área de estudo no Bairro de Boa Viagem. Nesta área foram definidos os pontos de referência por meio do método de levantamento por posicionamento GNSS relativo estático.

Figura 6 - Fluxograma dos procedimentos metodológicos.

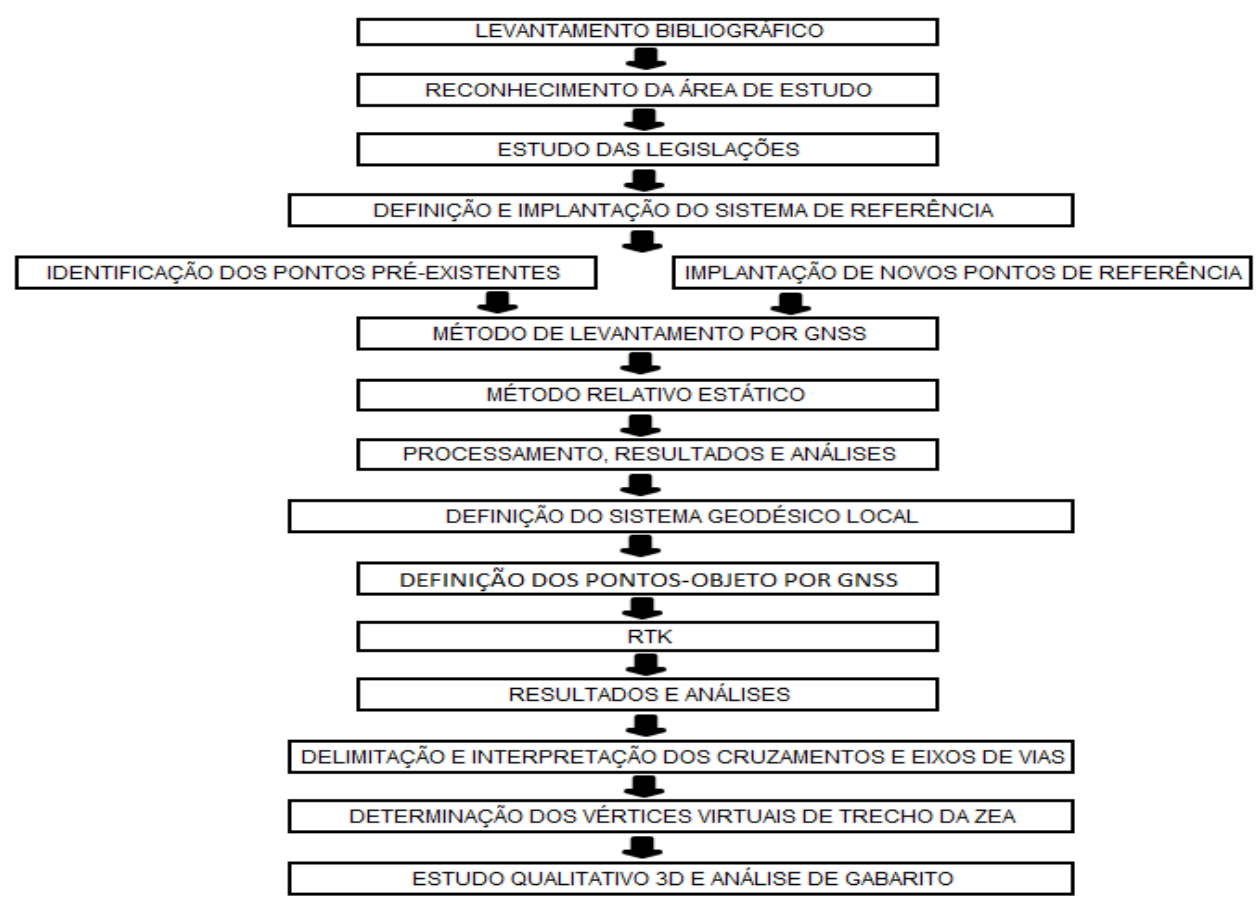

Fonte: Camilo Neto e De Seixas (2016). 
$\mathrm{Na}$ fase da definição e implantação do Sistema de Referência foram identificados os pontos de referência pré-existentes, V12 e V13, da PMCR, a estação RBMC-RECF e a materialização de novos pontos de referência (CS1, CC2, CV3, EB4, BD5 e BA6), que serviram de apoio aos levantamentos. O Método de posicionamento GNSS relativo estático serviu também para a definição de um Sistema Geodésico Local em SIRGAS2000. Os dados adquiridos foram processados e comparados. A partir dos pontos de referência foram definidos os pontos-objeto por intermédio do método de posicionamento GNSS/RTK para caracterizar os cruzamentos e com esses dados processados in loco foi possível delimitar e interpretar os eixos dos cruzamentos das vias, determinar os Vértices Virtuais do trecho da poligonal da ZEA em estudo e elaborar produtos cartográficos.

\subsubsection{MEDIÇÃO DOS PONTOS DE REFERÊNCIA: MÉTODO DE POSICIONAMENTO GNSS RELATIVO ESTÁTICO}

Nesta etapa foi realizado o georreferenciamento dos pontos de referência no trecho definido. Os dados foram coletados com os receptores GNSS (L1 e L2) nos vértices V12 e V13, da PMCR, e depois nos vértices CS1, CC2, CV3, EB4, BD5 e BA6, que estão materializados próximos aos cruzamentos de interesse (Figura 5).

Na medição foram utilizados quatro (4) receptores GNSS (L1 e L2), com taxa de gravação dos dados de 5 segundos e máscara de elevação de $15^{\circ}$. Os receptores foram instalados com tripés, bases nivelantes e adaptadores base-receptor, e em seguida foram medidas as alturas verticais das respectivas antenas integradas nos receptores utilizados. A campanha visou rastrear simultaneamente as estações existentes RBMC RECF, V12 e V13 (Figura 7), sendo que os dados da estação RBMC-RECF foram disponibilizados pelo IBGE (2017).

Figura 7 - Vista área das estações RBMC-RECF, V12 e V13.

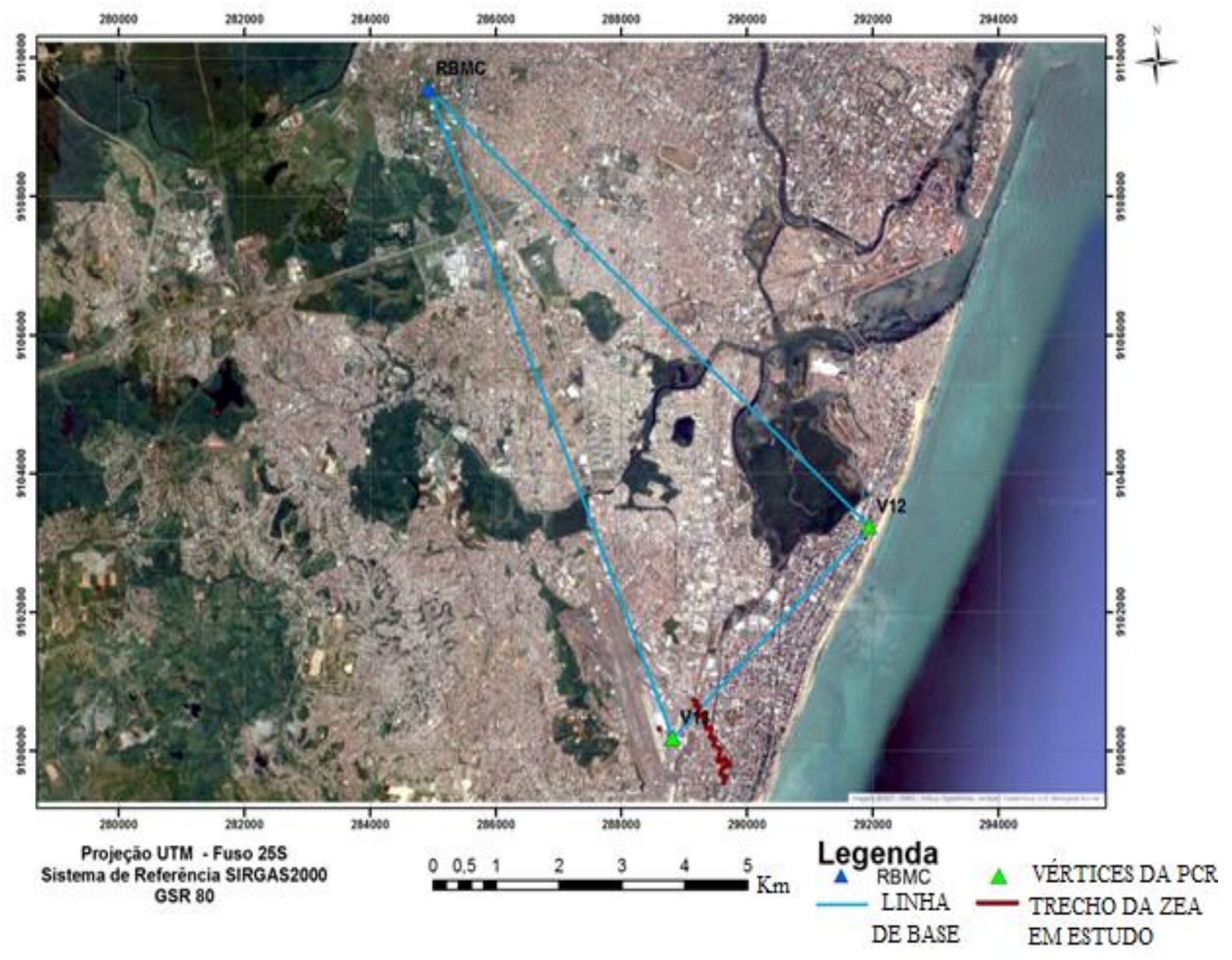

Fonte: Camilo Neto (2018). 
Foram utilizados 2 receptores Topcon Hiper V fixos para rastreio, de aproximadamente 8 horas, das estações V12 e V13, e o rastreio de aproximadamente 1 hora das estações implantadas, CS1, CC2, CV3, EB4, BD5 e BA6 que foram ocupadas sucessivamente pelos dois receptores Topcon Hiper Lite + sendo deslocados, respectivamente, a cada 1 hora (Figura 7) e (Figura 5).

Em (IBGE, 2008) são dadas as recomendações para a aplicação do posicionamento GNSS relativo estático e a precisão alcançada do posicionamento em função do comprimento da linha de base, do tempo de observação e do equipamento empregado.

O processamento e ajustamento dos vértices de referência existentes medidos foram realizados com o software TOPCON TOOLS 8.2 com um nível de confiança de 95\%, as estações geodésicas: V12 e V13 reprocessadas foram usadas como referências (Tabela 2).

O Sistema Geodésico Local ficou definido com a origem no vértice RBMC RECF: 803'03,46970"S, 3457'05,45910"W e a altitude elipsoidal de 20,180 m como sugerido em (MENDONÇA et al., 2010).

Para a definição do Sistema Geodésico Local foi utilizado o Módulo de Transformações de Coordenadas do software AstGeoTop (GARNÉS, 2013). No software é aplicada a equação de transformação de coordenadas geodésicas elipsoidais $(\phi, \lambda, h)$ em coordenadas no SGL $(\mathrm{x}, \mathrm{y}, \mathrm{h})$, definindo como a origem o vértice RBMC RECF e somando-se em seguida a estas $150.000,000 \mathrm{~m}$ no eixo $\mathrm{x}$ e $250.000,000 \mathrm{~m}$ no eixo y para achar as coordenadas no Sistema Geodésico Local (SGL).

\subsubsection{MEDIÇÃO DOS PONTOS-OBJETO: MÉTODO DE POSICIONAMENTO GNSS/RTK}

Nesta etapa foi realizado o levantamento dos pontos-objeto. Os dados foram armazenados na coletora a partir das bases instaladas nos vértices CS1, CC2, CV3, EB4, BD5 e BA6, que estão materializados próximos aos cruzamentos de interesse (Figura 5).

$\mathrm{Na}$ coletora foi definida a precisão para a coleta dos pontos-objeto através do posicionamento GNSS/RTK com solução fixa. Assim, foram definidas uma precisão planimétrica menor ou igual a $\pm 25 \mathrm{~mm}$ e uma precisão altimétrica menor ou igual a $\pm 30 \mathrm{~mm}$. A precisão para o posicionamento GNSS/RTK dos pontos-objeto, delimitadores dos cruzamentos das vias levantadas, foi limitada a essa ordem de grandeza, de acordo com as precisões alcançadas para esse tipo de procedimento em campo, quando o ambiente de medição é urbano e está envolvido por construções.

As denominações dos pontos-objeto foram dadas com base no ponto de origem seguido da letra A e uma sequencia numérica crescente. Foram feitas duas medidas por ponto para controle e melhoria da precisão, após a configuração da base e depois do receptor rover, com medição das alturas das antenas. Como em cada ponto foram feitas 2 leituras, a nomenclatura dos pontos-objeto vem seguida dos números 1 ou 2. Como exemplo dessa nomenclatura foram denominados os pontos coletados a partir do vértice CS1 como CS1A11, CS1A12 e assim, sucessivamente.

Os pontos-objeto foram extraídos da coletora com o software Topconlink v.8.2.3 em coordenadas plano - retangulares (UTM) - SIRGAS2000 e em seguida transformadas em coordenadas geodésicas elipsoidais $(\phi, \lambda \mathrm{e} h)$ com a ajuda do software AstGeoTop, também utilizado para as transformações geodésicas ao final utilizando como origem a RBMC RECF. Em média foram levantados 20 pontos por cruzamento com duas observações repetidas para cada ponto levantado.

\section{RESULTADOS E DISCUSSÕES}

A seguir são apresentados os resultados alcançados e respectivas análises para a realização da metodologia proposta para o posicionamento geodésico de ZEA no trecho do estudo de caso realizado.

\subsection{Determinação e Análise dos Pontos de Referência}

A Tabela 2 apresenta as coordenadas geodésicas e planorretangulares UTM em SIRGAS2000 das estações geodésicas: V12 e V13 determinadas com os dados levantados e comparadas com as pré-existentes fornecidas no Banco de Dados E-SIG da PRMR. 
Tabela 2 - Coordenadas Geodésicas e Planorretangulares UTM em SIRGAS2000 e altitude elipsoidal das Estações V12 e V13 ajustadas.

\begin{tabular}{c|c|c|c|c|c}
\hline \multirow{2}{*}{ Pontos } & \multicolumn{2}{|c|}{ COORDENADAS GEODÉSICAS } & \multicolumn{2}{c|}{ COORDENADAS UTM } & ALT. ELIP. \\
\cline { 2 - 6 } & LATITUDE $(\boldsymbol{\phi})$ & LONGITUDE $(\boldsymbol{\lambda})$ & $\mathbf{E}(\mathbf{m})$ & $\mathbf{N}(\mathbf{m})$ & h $(\mathbf{m})$ \\
\hline $\mathrm{V} 12$ & $8^{\circ} 06^{\prime} 30,16494 " \mathrm{~S}$ & $34^{\circ} 53^{\prime} 17,32461^{\prime \prime} \mathrm{W}$ & $291.946,791$ & $9.103 .236,979$ & $-1,433$ \\
\hline $\mathrm{V} 13$ & $8^{\circ} 08^{\prime} 09,33049 " \mathrm{~S}$ & $34^{\circ} 54^{\prime} 59,92550^{\prime \prime} \mathrm{W}$ & $288.819,654$ & $9.100 .175,344$ & 2,690 \\
\hline
\end{tabular}

Fonte: Camilo Neto (2018).

A Tabela 3 mostra as Coordenadas Geodésicas e Coordenadas no SGL (SIRGAS2000) dos pontos de referência implantados no trecho da ZEA em estudo e seus respectivos desvios padrão obtidos no processamento dos dados pelo software TOPCON TOOLS 8.2. As coordenadas e respectivos desvios padrão dos vértices denominados de CS1, CC2, CV3, EB4, BD5 e BA6, foram obtidos com o método de posicionamento GNSS relativo estático, com tempo de observação simultânea de 1h, utilizando-se como referência a estação da RBMC-RECF, vértice V-12 e vértice V-13 (Tabela 2).

Tabela 3 - Coordenadas geodésicas e coordenadas no SGL (SIRGAS2000).

\begin{tabular}{|c|c|c|c|c|c|c|c|c|}
\hline \multirow{2}{*}{ Pontos } & \multicolumn{3}{|c|}{ COORDENADAS GEODÉSICAS } & \multirow[b]{2}{*}{$\sigma \lambda(\mathbf{m})$} & \multicolumn{2}{|c|}{ COORDENADAS NO SGL } & \multicolumn{2}{|c|}{$\begin{array}{l}\text { ALTITUDE } \\
\text { ELIP. }\end{array}$} \\
\hline & Latitude $(\phi)$ & $\sigma \phi(\mathbf{m})$ & Longitude $(\lambda)$ & & $\mathbf{x}(\mathbf{m})$ & $\mathbf{y}(\mathbf{m})$ & $\mathbf{h}(\mathbf{m})$ & $\begin{array}{c}\boldsymbol{\sigma h} \\
(\mathbf{m})\end{array}$ \\
\hline CS1 & $8^{\circ} 08^{\prime} 19,884 " \mathrm{~S}$ & $\pm 0,005$ & $34^{\circ} 54^{`} 36,667^{\prime \prime} \mathrm{W}$ & $\pm 0,005$ & $154.554,920$ & $240.279,134$ & $-0,620$ & $\pm 0,007$ \\
\hline $\mathrm{CC} 2$ & $8^{\circ} 08^{`} 14,291 " \mathrm{~S}$ & $\pm 0,006$ & $34^{\circ} 54^{\prime} 35,061^{\prime \prime} \mathrm{W}$ & $\pm 0,005$ & $154.604,089$ & $240.450,960$ & $-0,509$ & $\pm 0,008$ \\
\hline $\mathrm{CV} 3$ & $8^{\circ} 08^{`} 09,765^{\prime \prime} \mathrm{S}$ & $\pm 0,009$ & $34^{\circ} 54^{\prime} 38,156^{\prime \prime} \mathrm{W}$ & $\pm 0,008$ & $154.509,375$ & $240.590,008$ & 1,687 & $\pm 0,011$ \\
\hline EB4 & $8^{\circ} 08^{`} 05,100^{\prime \prime} \mathrm{S}$ & $\pm 0,006$ & $34^{\circ} 54 ` 39,694^{\prime \prime} \mathrm{W}$ & $\pm 0,006$ & $154.462,288$ & $240.733,325$ & 1,745 & $\pm 0,007$ \\
\hline BD5 & $8^{\circ} 07^{`} 58,759^{\prime \prime} \mathrm{S}$ & $\pm 0,005$ & $34^{\circ} 54^{`} 45,939^{\prime \prime} \mathrm{W}$ & $\pm 0,005$ & $154.271,144$ & $240.928,134$ & 3,038 & $\pm 0,006$ \\
\hline BA6 & $8^{\circ} 07 ` 53,849^{\prime \prime} \mathrm{S}$ & $\pm 0,007$ & $34^{\circ} 54^{`} 48,055^{\prime \prime} \mathrm{W}$ & $\pm 0,007$ & $154.206,372$ & $241.078,994$ & 1,254 & $\pm 0,009$ \\
\hline
\end{tabular}

Fonte: Camilo Neto (2018).

Conforme a Tabela 3, os desvios padrão na latitude variam de \pm 5 a $\pm 9 \mathrm{~mm}$, os desvios padrão na longitude variam de \pm 5 a $\pm 8 \mathrm{~mm}$ e os desvios padrão na altitude elipsoidal variam de \pm 6 a $\pm 11 \mathrm{~mm}$, garantindo o posicionamento dos pontos de referência em módulo na ordem $\leq 11 \mathrm{~mm}$.

Além disso, foi realizada a verificação do erro de fechamento da rede através do comando "Loop Closures", onde foi evidenciado que as linhas de base são consistentes, com a discrepância máxima na horizontal de $9 \mathrm{~mm}$ no fechamento dos triângulos e na vertical a discrepância máxima foi de $29 \mathrm{~mm}$.

\subsection{Determinação e Análise dos Pontos-Objeto}

Nos pontos-objeto coletados a partir dos seis vértices (CS1, CC2, CV3, EB4, BD5 e BA6), observase que os desvios padrão na latitude variaram de $\pm 3 \mathrm{~mm}$ a $\pm 17 \mathrm{~mm}$, os desvios padrão na longitude variaram de $\pm 3 \mathrm{~mm}$ a $\pm 18 \mathrm{~mm}$ e os desvios padrão na altitude elipsoidal variaram de \pm 8 a $\pm 18 \mathrm{~mm}$, garantindo assim, o posicionamento dos pontos-objeto em módulo na ordem $\leq 18 \mathrm{~mm}$. Os desvios padrão indicados foram obtidos in loco nos pontos-objeto levantados com o método de posicionamento GNSS/RTK realizado. Observa-se que os mesmos foram determinados com uma qualidade posicional melhor do que a margem de precisão horizontal e vertical estabelecida para a determinação dos pontos-objeto (cf. item 4.2.2).

De acordo com Segantine (2005), a precisão média oferecida no posicionamento RTK é da ordem de $\pm(10 \mathrm{~mm}+1-2 \mathrm{ppm})$ para as coordenadas horizontais e $\pm(15-20 \mathrm{~mm}+2 \mathrm{ppm})$ para a componente vertical.

\subsection{Delimitação e Interpretação dos Cruzamentos e Eixos de Vias}

A partir dos dados dos pontos-objeto foram representados os detalhes das vias e seus cruzamentos. Com os cruzamentos definidos, foram realizadas as interseções das retas pelo método analítico para estabelecimento dos Vértices Virtuais. Esta etapa consiste no cálculo gráfico dos Vértices Virtuais (VV) por meio do Programa Auto CAD e no estudo qualitativo 3D e análise de gabarito. 


\subsubsection{CÁLCULO GRÁFICO DOS VÉRTICES VIRTUAIS (VV) POR MEIO DO PROGRAMA AUTO CAD}

Os pontos previstos da poligonal da ZEA encontram-se no cruzamento dos eixos das ruas descritas na Lei $\mathrm{n}^{\circ}$ 16.414, de 29 de Julho de 1998 (RECIFE, 1998), no estado atual apresentados em memorial descritivo, mas sem posicionamento geodésico, a serem localizados e analisados, porém, devido às vias serem movimentadas e com grande fluxo de veículos, foi desenvolvida uma metodologia para definir as coordenadas para o estabelecimento da Zona específica através dos Vértices Virtuais (cf. item 4). Estes são determinados analiticamente a partir da interpretação dos cruzamentos e eixos de vias (Figura 8). Para isso foi necessário:

a) o levantamento dos pontos-objeto de detalhes nos cruzamentos das vias com o método de posicionamento GNSS/RTK;

b) a definição dos eixos dos logradouros pela interseção dos pontos-objeto das laterais das vias (A,

$\mathrm{B}, \mathrm{C}$ e D); e

c) a definição dos pontos médios dos lados do polígono A, B, C e D.

A definição dos eixos dos logradouros foi feita considerando a interseção dos pontos-objeto das laterais das vias, formando as coordenadas da poligonal (A, B, C e D), conforme ilustrado na Figura 8, onde posteriormente foram traçadas as distâncias médias de cada lado da poligonal e pelas interseções dos pontos médios foram encontrados os cruzamentos que determinam os Vértices Virtuais. As Figuras 8A e 8B ilustram as formas de cruzamento existentes no trecho da ZEA em estudo.

Figura 8 - Formas de cruzamentos existentes no trecho levantado.

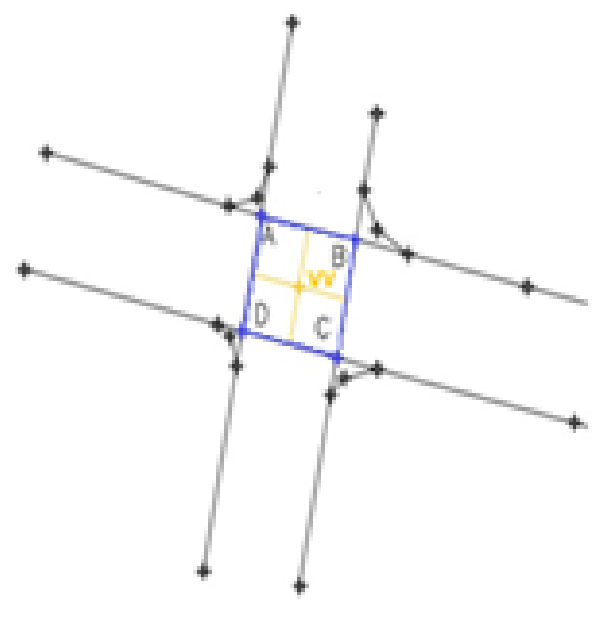

A - Cruzamento em "X"

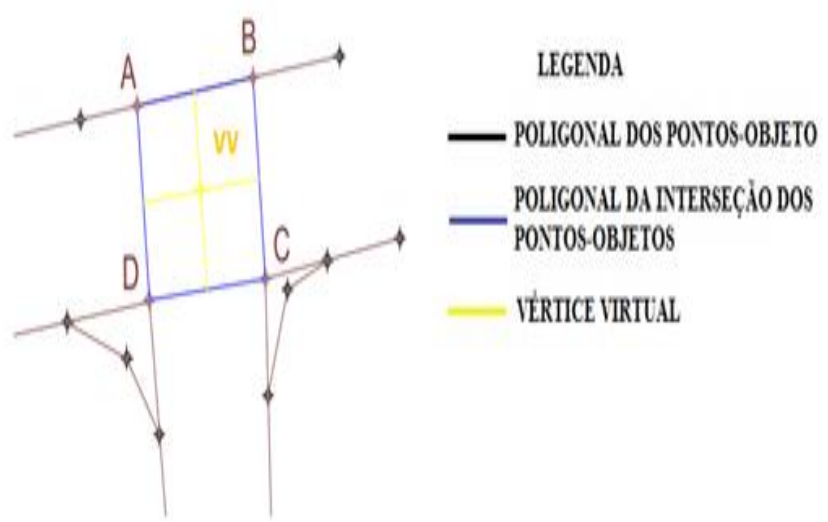

B - Cruzamento em "T"

Fonte: Camilo Neto (2018).

A Figura 9 é apresentada como modelo dos cruzamentos levantados. Nesta estão representados graficamente os pontos-objeto de detalhes levantados no cruzamento da via e determinados a partir do ponto de referência CV3, obtidos pelo método de posicionamento GNSS/RTK.

Figura 9 - Pontos-objeto de detalhes nos cruzamentos das vias (Rua SGT Valdir Coreia/Rua Conde de Vila Flor), a partir de CV3. 


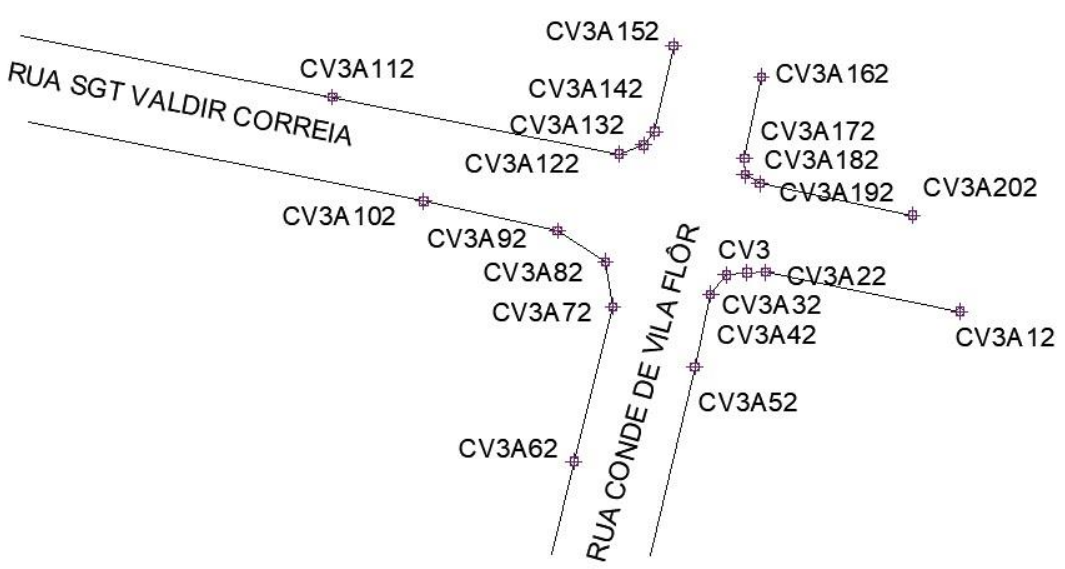

Fonte: Camilo Neto (2018).

\subsubsection{ESTUDO QUALITATIVO 3D E ANÁLISE DE GABARITO}

As construções, na região de estudo, mantêm de modo geral a altura média de 10 metros (equivalente a um prédio de 3 andares), apesar de existirem prédios com 30 metros de altura (equivalente a um prédio de 10 andares) dentro da área da ZEA, conforme observado na Figura 10, que mostra o cruzamento da rua Cosmorama com a rua Sideral (VV1) e o cruzamento da Cosmorama com a rua Copacabana (VV2).

Figura 10 - Cruzamento da Rua Sideral com a rua Cosmorama e cruzamento da rua Cosmorama com a rua Copacabana.

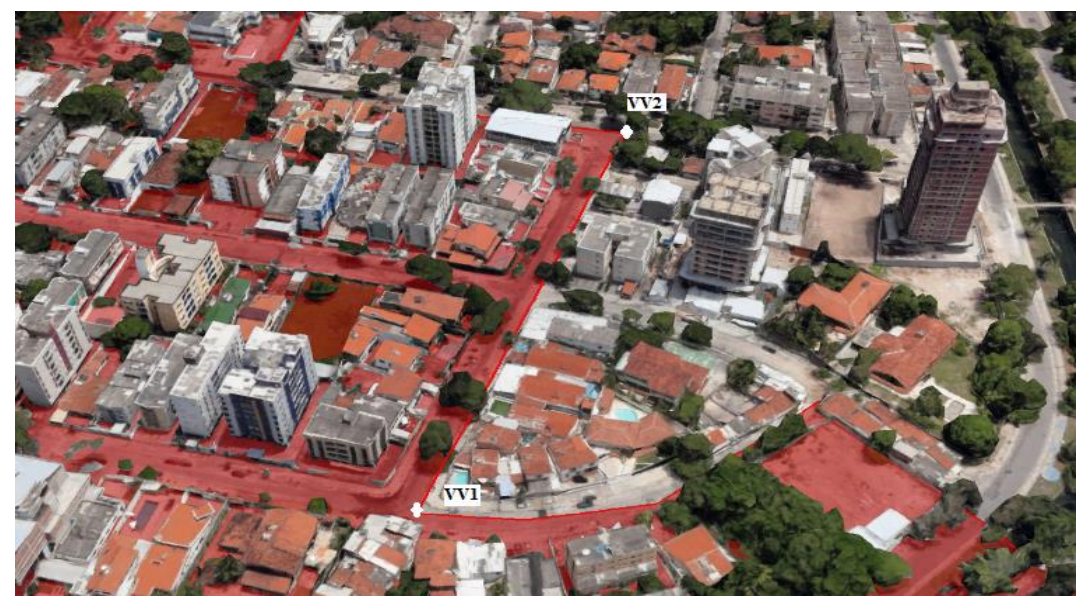

Fonte: Camilo Neto (2018).

A área da ZEA em estudo foi identificada dentro da superfície horizontal interna do Aeroporto Internacional dos Guararapes - Gilberto Freyre que está limitada às construções de obstáculos quando possuir altura superior a 25 metros em relação à elevação do aeródromo e se elevar acima da superfície do terreno em mais de 8 metros, previsto na Portaria n 957/GC3/2015 (BRASIL, 2015), mostrado na Figura 11. 
Figura 11 - Gabarito dentro da Superfície Horizontal Interna.

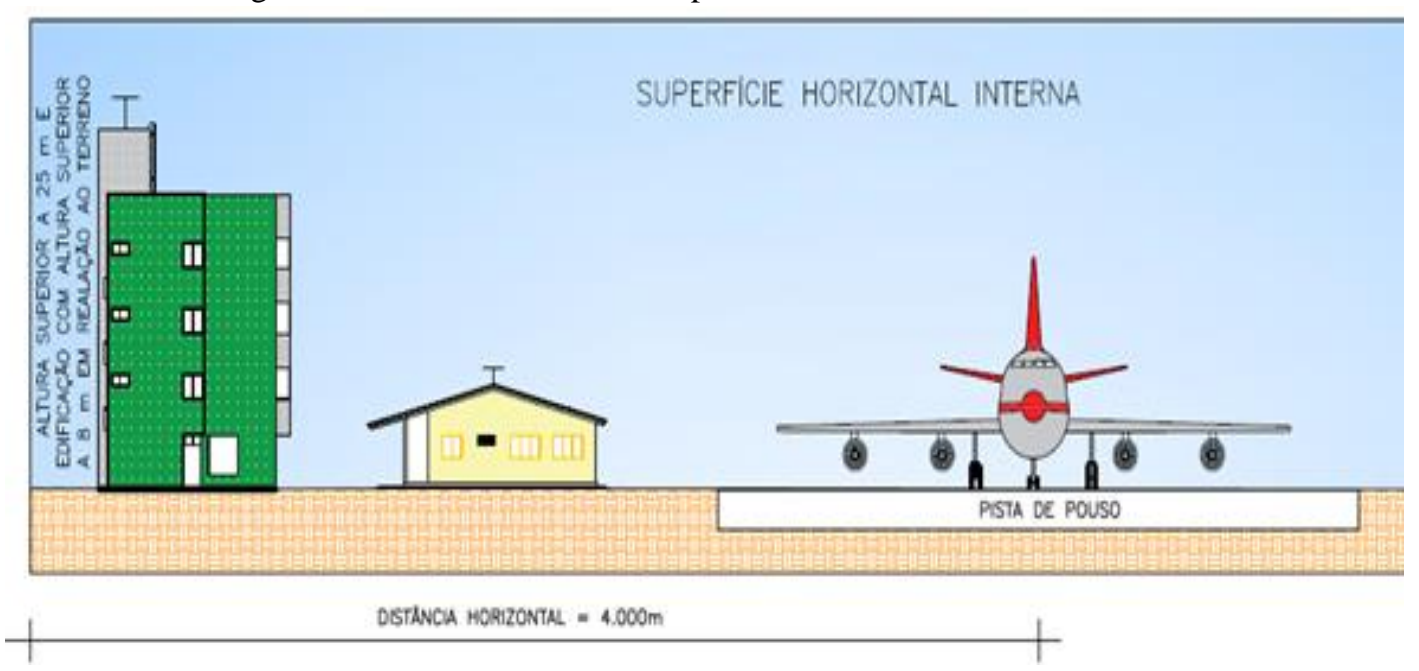

Fonte: Camilo Neto (2018).

\subsection{Determinação dos Vértices Virtuais do Trecho da ZEA em Estudo}

Com a definição dos cruzamentos e a definição dos pontos médios (cf. item 5.3.1) foi possível determinar o Vértice Virtual, ponto descrito na legislação municipal da Cidade do Recife como vértice da poligonal que compõe a ZEA. Com os cruzamentos definidos e os pontos de interseção das retas encontrados no programa Autocad2016, conforme apresentado no item 5.3.1, foi calculada a média das coordenadas e delimitado cada Vértice Virtual do trecho da ZEA levantado, que estabelece o ponto da poligonal da ZEA. O Vértice Virtual foi determinado pela intersecção do eixo das vias, a partir da medição de dois pontos no meio fio: um antes do início da curva e o outro o próprio início de curva (Figura 8 e Figura 9). E isso deve seguir a descrição da norma e das respectivas vias envolvidas nos cruzamentos. Os valores encontrados pelo método gráfico são descritos na Tabela 4. As coordenadas obtidas pelo método gráfico foram constatadas pelo método analítico de interseção de retas.

Tabela 4 - Vértice Virtual obtido pelo método analítico usando o método de posicionamento GNSS/RTK.

\begin{tabular}{|c|c|c|c|}
\hline \multirow{2}{*}{ Nomes das vias } & \multirow{2}{*}{$\frac{\text { Vértices }}{\text { Virtuais }}$} & \multicolumn{2}{|c|}{$\begin{array}{c}\text { Coordenadas no SGL SIRGAS2000 - } \\
\text { Método gráfico }\end{array}$} \\
\hline & & $\mathbf{X}(\mathbf{m})$ & $\mathbf{Y}(\mathbf{m})$ \\
\hline Rua Sideral / Rua Cosmorama & VV1 & $154.548,321$ & $240.275,257$ \\
\hline Rua Cosmorama / Rua Copacabana & VV2 & $154.611,964$ & $240.454,325$ \\
\hline Rua Copacabana / Rua Conde Vila Flor & VV3 & $154.481,145$ & $240.486,642$ \\
\hline Rua Conde de Vila Flor / Rua Sgt. Valdir Correia & VV4 & $154.504,569$ & $240.594,915$ \\
\hline Rua Sgt. Valdir Correia / Rua Eng. Lauro Borba & VV5 & $154.432,458$ & $240.610,968$ \\
\hline Rua Eng. Lauro Borba / Rua Barão de Beberibe & VV6 & $154.458,059$ & $240.739,621$ \\
\hline Rua Barão de Beberibe / Rua Waldemar N. C. Monteiro & VV7 & $154.362,445$ & $240.761,308$ \\
\hline Rua Waldemar N. C. Monteiro / Rua Barão de S. Leão & VV8 & $154.335,483$ & $240.931,407$ \\
\hline Rua Barão de S. Leão / Rua Dr. Luiz Correia de Oliveira & VV9 & $154.226,145$ & $240.918,503$ \\
\hline Rua Dr. Luiz Correia de Oliveira / Rua Barão de Tefé & VV10 & $154.258,569$ & $241.068,828$ \\
\hline Rua Barão de Tefé / Rua Aranã & VV11 & $154.200,420$ & $241.083,547$ \\
\hline Rua Aranã / Rua Adalto C. leal & VV12 & $154.218,662$ & $241.149,828$ \\
\hline
\end{tabular}

Fonte: Camilo Neto (2018).

\section{CONCLUSÕES}

No trecho da ZEA posicionado neste trabalho, além da identificação e estudo dessa parte importante do zoneamento municipal, a região foi contemplada com a implantação e densificação de novos pontos de 
referência.

Com a interpretação e a análise gráfica das legislações foi possível definir o trecho previsto para este trabalho. O levantamento com o emprego de receptores GNSS no método de posicionamento Relativo Estático se apresentou pertinente para o posicionamento dos pontos de referência implantados e o levantamento pelo método de posicionamento GNSS/RTK se mostrou adequado à obtenção dos pontosobjeto para o detalhamento dos cruzamentos das vias e estabelecimento dos Vértices Virtuais da ZEA.

Os experimentos mostraram que os desvios padrão na latitude variaram de $\pm 5 \mathrm{a} \pm 9 \mathrm{~mm}$, na longitude variaram de \pm 5 a $\pm 8 \mathrm{~mm}$ e na altitude elipsoidal variaram de \pm 6 a $\pm 11 \mathrm{~mm}$, garantindo o posicionamento dos pontos de referência implantados (CS1, CC2, CV3, EB4, BD5 e BA6) em módulo na ordem $\leq 11 \mathrm{~mm}$. Nos pontos-objeto, observa-se que os desvios padrão na latitude variaram de $\pm 3 \mathrm{~mm} \mathrm{a} \pm 17 \mathrm{~mm}$, os desvios padrão na longitude variaram de $\pm 3 \mathrm{~mm} \mathrm{a} \pm 18 \mathrm{~mm}$ e os desvios padrão na altitude elipsoidal variaram de \pm 8 a \pm 18 $\mathrm{mm}$, garantindo assim, o posicionamento em módulo na ordem $\leq 18 \mathrm{~mm}$. Conforme a metodologia desenvolvida e levando em consideração as análises feitas para os resultados, conclui-se que os pontos de referência, obtidos com o uso dos receptores GNSS, podem ser utilizados para o georreferenciamento de imóveis e objetos existentes na área da ZEA, favorecendo o cumprimento da NBR 14166/1998 (ABNT, 1998) e monitoramentos das construções, conforme Lei Municipal $\mathrm{n}^{\circ} 16414$, de 29 de julho de 1998 (RECIFE, 1998) e Portaria $n^{\circ}$ 957/GC3/2015 (BRASIL, 2015) do Comando da Aeronáutica. As vantagens desse método se faz presente na rapidez da coleta dos dados de campo com posterior processamento, a possibilidade de levantamento sem a intervisibilidade de trechos, pois sempre existem obstáculos e o próprio trânsito intenso dificulta os serviços em vias urbanas e outra vantagem é que neste sistema é possível no momento do levantamento RTK saber a precisão dos dados.

Ao Avaliar as legislações urbanísticas municipais e sua relação com as restrições impostas a ZEA, percebe-se um conflito entre as normativas e que apesar do estado exercer um importante papel na organização do espaço urbano, normatizando e regularizando as ações dos atores públicos e privados, faltam na região da Zona Especial do Aeroporto definição de parâmetros e instrumentos urbanísticos específicos para o estabelecimento de obras naquela área.

Com o desenvolvimento da metodologia para determinação de coordenadas dos Vértices Virtuais da poligonal do trecho da ZEA em análise foi possível chegar às coordenadas no Sistema Geodésico Local para estabelecimento dos limites do Zoneamento e possibilidade de implementação de projetos em engenharia e cadastros na região.

Conforme a metodologia e levando em consideração as análises feitas para os resultados, conclui-se que as coordenadas dos Vértices Virtuais determinadas a partir de pontos-objeto dos cruzamentos das vias levantados pelo método de posicionamento GNSS/RTK foram satisfatórias e realizadas com a interseção dos pontos coletados do trecho da ZEA, conforme Lei Municipal n 16.414, de 29 de julho de 1998 (RECIFE, 1998).

Para perspectivas futuras de trabalhos, recomendam-se alguns estudos complementares para o tema investigado, tais como:

a) a verificação da acurácia alcançada com o método de posicionamento GNSS/RTK por meio do levantamento de pontos com coordenadas conhecidas;

b) a determinação das coordenadas altimétricas dos Vértices Virtuais a partir da interseção analítica e verificação das respectivas discrepâncias altimétricas das interseções realizadas;

c) a utilização de dados LiDar do Levantamento PE 3D do estado e a confrontação com pontos de controle para a verificação do Modelo Digital de Superfície;

d) a determinação dos pontos-objeto dos cruzamentos em Rede RTK.

\section{Agradecimentos}

Os autores agradecem ao Programa de Pós Graduação em Ciências Geodésicas e Tecnologias da Geoinformação (PPGCGTG) da UFPE e à CAPES pela realização do Curso de Pós-Graduação e ao Projeto de Pesquisa intitulado a Geodésia Aplicada à Discretização de Edificações Prediais e o Estabelecimento de Padrões de Referência Metrológica - processo nº 23076.011861/2017-91 PROPESQ/UFPE. Ao Laboratório 
de Geodésia (LAGEO) e Laboratório de Topografia (LATOP) pela concessão dos equipamentos e acessórios. Ao professor Dr. Silvio Jacks dos Anjos Garnés pela licença de software AstGeoTop, ao MSc. Alexandre Nascimento, Msc. Ermerson de Vasconcelos Silva, ao Eng. Alex Souza e à Técnica Denise Barbosa de Lima pela contribuição com os levantamentos geodésicos.

\section{Contribuição dos Autores}

Os autores elaboraram a metodologia e participaram de todos os experimentos e coleta de dados. O autor Raimundo Nonato Camilo Neto projetou o experimento, escreveu o manuscrito e foi responsável pela contextualização e revisão da literatura. A autora Andréa de Seixas orientou o desenvolvimento do projeto, executou a análise formal, a supervisão, a revisão e edição deste artigo.

\section{Conflitos de Interesse}

Os autores declaram que não há conflitos de interesse.

\section{Referências}

ABNT: NBR 14.166. Rede de Referência Cadastral Municipal - Procedimento. Rio de Janeiro. 1998.

ALVES, D. B. M.; DALBELO, L. F. A.; MONICO, J. F. G.; SHIMABUKURO, M. H. First Brazilian Real Time Network DGPS through the Internet: Development, Application and Availability Analyses. Journal of Geodetic Science. v. 1, p. 1-7, issn: 2081-9919, 2011. DOI: https://doi.org/10.2478/v10156011-0018-7.

ANDRADE, L. S.; ALVES, D. B. M. Novas Observáveis GPS e a Melhoria na Acurácia do Posicionamento. RBC. Revista Brasileira de Cartografia (Online), v. 68, p. 991-1004, 2016.

BRASIL. Lei $\mathrm{n}^{\circ}$ 21.713, de 27 de agosto de 1946. Promulga a Convenção sobre Aviação Civil Internacional.

BRASIL. Lei $\mathrm{n}^{\circ}$ 7.565, de 19 de dezembro de 1986. Dispõe sobre o Código Brasileiro de Aeronáutica (CBA).

BRASIL. Portaria $n^{\circ}$ 1.141/GM5, de 8 de dezembro de 1987. Dispõe e aprova as Zonas de Proteção (PBZPA e PBZR).

BRASIL. Constituição Federal, de 05 de outubro de 1988. Constituição da República Federativa do Brasil.

BRASIL. Portaria DAC no 232/DGAC, de 14 de abril de 1997. Aprova o Plano Específico de Zoneamento de Ruído do Aeroporto Internacional dos Guararapes - PE.

BRASIL. Lei n 16.414, de 29 de julho de 1998. Dispõe sobre as condições de Uso e Ocupação do Solo na Zona Especial do Aeroporto - ZEA.

BRASIL. Lei no 11.182, de 27 de setembro de 2005. Cria a Agência Nacional de Aviação Civil - ANAC.

BRASIL. Portaria $n^{\circ}$ 76/DGCEA, de 09 de junho de 2005. Aprova o Plano Específico da Zona de Proteção do Aeródromo de Recife/Guararapes - Gilberto Freyre.

BRASIL. Portaria $n^{\circ}$ 256, de 13 de maio de 2011. Dispõe sobre as restrições relativas às implantações que possam afetar adversamente a segurança e a regularidade das operações aéreas.

BRASIL. Regulamento Brasileiro da Aviação Civil $\mathbf{n}^{\mathbf{0}}$ 161, Resolução ANAC $n^{\circ}$ 281, de 10 de setembro de 2013. Plano de Zoneamento de Ruído de Aeródromos - PZR.

BRASIL. Portaria $N^{\circ}$ 957/GC3, de 9 de julho de 2015. Dispõe sobre as restrições aos objetos projetados no espaço aéreo que possam afetar adversamente a segurança ou a regularidade das operações aéreas. 
BRASIL. Portaria $\mathrm{n}^{\circ}$ 1.255/SIA, de 20 de maio de 2016, da ANAC. Valida curvas de ruído para o Aeroporto Internacional Guararapes - Gilberto Freyre, localizado em Recife/PE - SBRF.

CAMILO NETO, R. N.; DE SEIXAS, A. Análise e discussão das normalizações para o estabelecimento da zona especial aeroportuária - ZEA, do aeroporto internacional do Recife/Guararapes - PE. In: Simpósio Brasileiro de Ciências Geodésicas e Tecnologias da Geoinformação, VI, 2016, Recife. Anais... Recife, 2016.

CAMILO NETO, R. N. Posicionamento Geodésico de Zonas Especiais Aeroportuárias - ZEA: uma metodologia aplicada ao aeroporto internacional do Recife/Guararapes no estado de Pernambuco. Dissertação (Mestrado em Ciências Geodésicas e Tecnologias da Geoinformação) - Universidade Federal de Pernambuco, 2018.

CONTRERAS-ALONSO, M. R.; EZQUERRA-CANALEJO, A.; MARTIN, E. P.; HERRERO-TEJEDOR, T. R.; MEDINA, S. L. C. Environmental assessment of Obstacle Limitation Surfaces (OLS) in airports using geographic information technologies. PLOS ONE | https://doi.org/10.1371/journal.pone.0229378 February 26, 2020.

DAL'FORNO, G. L.; AGUIRRE, A. J.; HILLEBRAND, F. L.; GREGORIO, F. V. Transformação de coordenadas geodésicas em coordenadas no plano topográfico local pelos métodos da Norma NBR 14166:1998 e o de rotações e translações. In: Simpósio Brasileiro de Ciências Geodésicas e Tecnologias da Geoinformação, III , Recife. Anais... Recife, 2010.

DISTEFANO N.; LEONARDI S.; BUSCEMA D. PROPOSAL OF A METHODOLOGY FOR AIRPORT PUBLIC SAFETY ZONES POLICY. INTERNATIONAL SIIV CONGRESS - PALERMO (ITALY), $4^{\text {th }}, 2007$. Anais... 12-14 SEPTEMBER 2007.

FALAVIGNA, G. P.; IESCHECK, A. L.; SOUZA, S. F. 3D MODELING TO IDENTIFY AND QUANTIFY OBSTACLES IN AERODROME PROTECTION ZONE. Bulletin of Geodetic Sciences, 26(2): e2020009, 2020. DOI 10.1590/s1982-21702020000200009

GARNÉS, S. J. A.; SIQUEIRA, V. P.; CACHO, J. P. Definição para implantação do sistema topográfico local de Campo Grande - MS e análise das fórmulas da NBR 14166. In: Colóquio Brasileiro de Ciências Geodésicas, IV, Curitiba - PR, 2005. Anais... Curitiba: Departamento de Geomática da UFPR, 2005.

GARNÉS, S. J. A. AstGeoTop. Software (Módulo: Transformações de Coordenadas). Recife-PE: Departamento de Engenharia Cartográfica. Universidade Federal de Pernambuco. 2013.

GARNÉS, S. J. A. Software AstGeoTop, 2017.

IESCHECK, A. L.; OLIVEIRA, A. L. S. Geographic Information System for 3D Modeling of the Specific Airport Protection Zone Plan and Urban Planning. In: International Cartographic Conference, 25th, 2011. Anais... Paris, France, 3-8 July 2011.

IBGE. Resolução PR n 01 - Altera a caracterização do Sistema Geodésico Brasileiro, 2005.

IBGE - Instituto Brasileiro de Geografia e Estatística. Recomendações Para Levantamentos Relativos Estáticos - GPS. Rio de Janeiro - RJ, 2008.

IBGE - Instituto Brasileiro de Geografia e Estatística. Disponível em: <https://ww2.ibge.gov.br/home/geociencias/download/tela_inicial.php?tipo=8>. Acesso em: 29 mai. 2017.

INTERNATIONAL CIVIL AVIATION ORGANIZATION - ANNEX 14 - Aerodrome Design and Operations. Canadá, 2009.

KAHMEN, H., FAIG, W. Surveying. Berlin. 1988. Ed. de Gruyter.

MENDONCA, F. J. B. ; GARNÉS, S. J. A. ; PEREIRA, C. M. ; BARROSO NETO, J. A. ; MELO, W. D. A. Análise do Ajustamento por Mínimos Quadrados de uma Trilateração Topográfica com Injunções nos planos UTM e Topocêntrico. In: Simpósio Brasileiro de Ciências Geodésicas e Tecnologias da Geoinformação, III, 2010, RECIFE. Anais... Recife, 2010.

MONICO, J. Posicionamento pelo GNSS: descrição, fundamentos e aplicações. São Paulo - SP: Editora 
Unesp, 2008.

RECIFE. Lei no 16.414, de 29 de julho de 1998. Dispõe sobre as condições de Uso e Ocupação do Solo na Zona Especial do Aeroporto - ZEA e dá outras providências.

RECIFE. Lei nº 16.176, de 09/05/1996. Estabelece a Lei de Uso e Ocupação do Solo da Cidade do Recife - LUOS.

RECIFE. Lei $\mathrm{n}^{\circ}$ 17.511/2008 (Plano Diretor do Município do Recife). Promove a Revisão do Plano Diretor do Município do Recife.

RECIFE. Lei n ${ }^{\circ}$ 18.338/2017. Dispõe sobre as condições de uso e ocupação do solo na Zona Especial do Aeroporto - ZEA.

SEEBER, G. Satellite Geodesy: Fundamentations, Methods and Applications. Walter de Gruyter, Berlin, New York, 2003.

SEGANTINE, P. GPS: Sistema de Posicionamento Global. São Carlos - SP: Editora EESC/USP, 2005.

SOUZA, A. N.; GARNÉS, S J A; MARQUES, H. A. Avaliação do Posicionamento GNSS obtido pelos Métodos Cinemáticos RTK/NTRIP e PPP em tempo real. Revista Brasileira de Cartografia (Online), v. 66, p. 1117, 2014.

SILVA, G. P.; De SEIXAS, A.; GARNES, S. J. A.; ROMAO, V. M. C. Definição do sistema de referência para a locação de edificações prediais - área experimental: Bairro da Madalena, Recife - PE. Revista Brasileira de Cartografia (Online), v. 67, p. 19, 2015.

SILVA, H. R.; MONICO, J. F. G.; Alves, D.B.M. Análise do Desempenho do RTK em Rede no Brasil sob Efeito da Cintilação Ionosférica. Revista Brasileira de Cartografia (Online), v. 68, p. 2083-2102, 2016.

TOPCON POSITIONING SYSTEMS. HiPer Lite Operator's Manual. June, 2003. Disponível em: https://fccid.io/LCB-840802/User-Manual/Users-Manual-346893. Acesso: em 05 out. 2018.

ZHU, N.; MARAIS, J.; BETAILLE, D.; BERBINEAU, M. GNSS Position Integrity in Urban Environments: A Review of Literature. IEEE Transactions on Intelligent Transportation Systems, 2018, 17p. ff10.1109/TITS.2017.2766768ff. ffhal-01709519f

WILlGALIS, Stefan ; SEEBER, Günter ; KRUEGER, Claudia Pereira ; ROMÃO, Veronica Maria Costa . A Real Time GPS Reference Network for Cadastral Surveys in Recife, Brazil. Revista Brasileira de Cartografia, Rio de Janeiro, v. 55, n.1, p. 1-10, 2003.

\section{Biografia do autor principal}

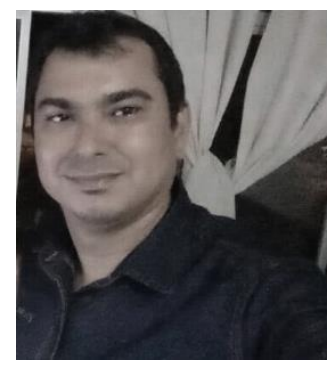

Raimundo Nonato Camilo Neto, natural de Fortaleza, Ceará, nascido em 14 de setembro de 1980. Mestre em Ciências Geodésicas e Tecnologias da Geoinformação (UFPE). Pós-graduado em Ensino Interdisciplinar das Ciências (UFRPE). Graduado em Engenharia Civil pela Universidade Estácio de Sá e Graduado em Ciências Biológicas pela UFRPE. Atua nas áreas de Educação, Meio Ambiente, Topografia, Cadastro, Avaliação, Projetos de Engenharia, Geoprocessamento e Geodésia. 